\title{
Ontogenia da semente de Tabebuia ochracea (Cham.) Standl. (Bignoniaceae)
}

\author{
DIANA SALLES SAMPAIO ${ }^{1,4}$, MARIA EUGÊNIA COSTA ${ }^{2}$ e \\ ADELITA APARECIDA SARTORI PAOLI ${ }^{3}$
}

(recebido: 09 de fevereiro de 2006; aceito: 03 de maio de 2007)

\begin{abstract}
Seed ontogeny in Tabebuia ochracea (Cham.) Standl. (Bignoniaceae)). The present work describes seed ontogeny in $T$. ochracea through histological analysis with special reference to the endospermogenesis. The ovule is anatropous, unitegmic and tenuinucelate; hypostase, nutrient passage route and endothelium are present. The endosperm is cellular with posterior development of Catalpa type. The chalazal haustorium of endosperm is primary, bicellular and it is totally degenerated during seed maturity; on the contrary the micropylar one is secondary, multicellular, differentiates latter, and remains active until the seed maturity. A latter differentiated endosperm was observed forming, together with the endothelium, a membranaceous envelope of the embryos. The endospermogenesis are in accord with previous results from other species of Tabebuia. Furthermore, the micropylar haustorium diferentiation and the membranaceous envelope origin were elucidated, the latter probably is the same in other species that present this structure.
\end{abstract}

Key words - Bignoniaceae, endosperm, ontogeny, seed, Tabebuia ochracea

RESUMO - (Ontogenia da semente de Tabebuia ochracea (Cham.) Standl. (Bignoniaceae)). O presente trabalho descreveu a ontogenia da semente de $T$. ochracea através de análises histológicas com especial referência a endospermogênese. Os óvulos são anátropos unitegumentados e tenuinucelados; hipóstase, rota de passagem de nutrientes e endotélio estão presentes. O endosperma é celular com desenvolvimento posterior do tipo Catalpa. O haustório calazal do endosperma é primário, bicelular e apresenta-se totalmente degenerado durante a maturidade da semente; já o micropilar é secundário, multicelular, diferencia-se tardiamente e está ativo até a maturidade da semente. Foi observado um endosperma diferenciado tardiamente formando, juntamente com o endotélio, um envoltório membranáceo dos embriões. A endospermogênese corresponde ao encontrado para outras espécies do gênero. Além disso, a diferenciação do haustório micropilar e a origem do envoltório membranáceo são elucidadas e, a última, provavelmente é a mesma nas espécies que apresentam essa estrutura.

Palavras-chave - Bignoniaceae, endosperma, ontogenia, semente, Tabebuia ochracea

\section{Introdução}

A identificação de sementes por meio de características morfológicas é importante na sistemática e taxonomia (Esau 1985), no entendimento da fisiologia da semente, em paleobotânica, arqueologia, fitopatologia, em análises na agricultura e horticultura, bem como no estudo de comunidades vegetais (Silva \& Paoli 2000). Entretanto, a compreensão da constituição histológica nas sementes maduras está vinculada à realização de estudos ontogenéticos (Fahn 1990).

1. Universidade Federal de Uberlândia, Campus Umuarama, Instituto de Biologia, Bloco 2D, Programa de Pós-Graduação em Ecologia e Conservação de Recursos Naturais, Sala 26, Caixa Postal 593, 38400-902 Umuarama, Uberlândia, MG, Brasil.

2. Universidade Estadual de Ponta Grossa, Setor de Ciências Biológicas e da Saúde, Departamento de Biologia Geral, Av. Carlos Cavalcante 4748, 84030-900 Ponta Grossa, PR, Brasil.

3. Universidade Estadual Paulista, Instituto de Biociências, Departamento de Botânica. Av. 24-A 1515, 13506-900 Rio Claro, SP, Brasil.

4
Investigações embriológicas em Bignoniaceae são escassas, principalmente em relação à endospermogênese (Shivaramiah 1998). As informações disponíveis sobre a endospermogênese não fornecem detalhes em relação aos estádios mais avançados de desenvolvimento, gerando equívocos na interpretação das estruturas na semente madura. As variações na diferenciação do haustório micropilar do endosperma, por exemplo, resultam em diferentes classificações segundo o sistema de Di Fulvio (1983). A membrana que envolve os embriões tem origem duvidosa, sendo reportada ao endosperma e ao nucelo em Pyrostegia venusta (Kergawl.) Miers (Gabrielli \& Castro 1995); ao endosperma, remanescentes do nucelo e do tegumento interno em Distictella mansoana (DC.) Urb. (Beltrati \& Piccolo 1979); ao endosperma e ao endotélio em Tabebuia chrysotricha (Mart. ex A. DC.) Standl. (Souza et al. 2005) e, a poucas camadas do endosperma em Tabebuia rosea (Bertol.) A. DC. (Mehra \& Kulkarni 1985) e Tabebuia serratifolia (Vahl) G. Nicholson (Costa 1995), como ocorre na maioria das espécies de Bignoniaceae (Hyakutake \& Grotta 1965, Panizza 1967, Mehra \& Kulkarni 1985). Estas diferentes interpretações 
da origem da membrana que envolve os embriões evidenciam a necessidade de maiores investigações a seu respeito.

Dois tipos de formação do endosperma foram estabelecidos na família Bignoniaceae: o tipo Catalpa, com haustórios de duas a quatro células, e o Incarvillea, com haustórios de apenas uma célula (Mauritzon 1935). Após o trabalho de Mauritzon, foram publicados os seguintes estudos que abrangem o tema endosperma em Bignoniaceae: o de Swamy (1941) com Bignonia megapotamica Spreng; o de Govindu (1950) com Jacaranda mimosifolia D. Don, Parmentiera cereifera Seem. e Tecoma stans (L.) Juss. ex Kunth.; o de Ghatak (1956) com Oroxylum indicum (L.) Kurz.; o de Mehra \& Kulkarni (1985) com T. rosea, Millingtonia hortensis L.F., Dolichandrone falcata Seem., Heterophragma adenophyllum (Wall. ex G. Don) Seem. ex Benth. \& Hook. f., Stereospermum chelonoides DC.; o de Shivaramiah (1998) com Kigelia pinnata (Jacq.) DC., Tecoma smithii, Campsis radicans (L.) Seem., Bignonia unguis-cati L., M. hortensis, Dolichandrone platycalyx Baker, Tabebuia pallida (Lindl.) Miers e Parmentiera edulis Raf.; o de Bittencourt Júnior et al. (2003) com Spathodea campanulata P. Beauv.; o de Bittencourt Júnior \& Semir (2005) com Tabebuia impetiginosa (Mart. ex DC.) Standl; e o de Souza et al. (2005) com T. chrysotricha. O tipo Catalpa com pequenas variações parece ser o representativo para Tabebuia.

Apesar de o gênero Tabebuia ser formado por aproximadamente 100 espécies (Gentry 1992), foram realizadas investigações sobre ontogenia da semente apenas em T. rosea (Mehra \& Kulkarni 1985), Tabebuia pulcherrima Sandwith (Bittencourt Júnior \& Mariath 2002), T. serratifolia (Costa 1995), T. pallida (Shivaramiah 1998), T. impetiginosa (Bittencourt Júnior \& Semir 2005) e T. chrysotricha (Souza et al. 2005). Tabebuia ochracea (Cham.) Standl. é um ipê amarelo típico do cerrado com ampla distribuição; tem aplicabilidade nas indústrias madeireira e farmacêutica, além de ser muito apreciado como ornamental (Lorenzi 2000). Assim, o estudo da ontogenia da semente em $T$. ochracea, justifica-se pela escassez de estudos sobre ontogenia da semente no gênero, pela importância ecológica e econômica da espécie e, também, por viabilizar comparações com $T$. chrysotricha, espécie considerada taxonomicamente próxima de $T$. ochracea (Gentry 1992). T. chrysotricha e T. ochracea ainda representam exceções na família, por apresentarem apomixia e sementes poliembriônicas (Costa et al. 2004, Souza et al. 2005).
O presente trabalho tem como objetivo descrever a ontogenia da semente de $T$. ochracea, elucidando os estádios da endospermogênese até a maturidade. Acredita-se que os dados aqui obtidos auxiliarão no esclarecimento de algumas questões, como a diferenciação do haustório micropilar do endosperma, a origem da membrana que envolve os embriões e a delimitação da região da hipóstase, além de contribuir para a taxonomia de Bignoniaceae.

\section{Material e métodos}

Terminologia - Diversas confusões ocorrem na interpretação da estrutura denominada hipóstase na região calazal da semente. O conceito de hipóstase sensu stricto corresponde a um grupo de células nucelares com paredes espessadas localizadas na extremidade calazal do saco embrionário, podendo ter um papel na nutrição do mesmo; enquanto o conceito de hipóstase sensu lato, corresponde a células nucelares na região calazal que formam uma placa celular discóide, passam por uma proliferação secundária e tem participação no desenvolvimento do tegumento da semente, podendo funcionar na proteção do embrião (Von Teichman 1988 apud Von Teichman \& Van Wyk 1991). Optou-se por utilizar o conceito de hipóstase sensu stricto neste estudo, por facilitar a interpretação dos resultados (Von Teichman \& Van Wyk 1991).

Coleta - Botões florais em pré-antese, flores e frutos em diversos estádios de desenvolvimento foram coletados no Estado de Minas Gerais entre os meses de agosto a outubro nos anos de 1999 e 2000. As coletas foram realizadas em populações da Serra do Cipó, no Município de Santana do Riacho (BHCB 68097 e 68098) - 19¹8'19”'S, 43³6'17” W, do Município de Pedro Leopoldo, na região da Gruta do Baú (BHCB 68100 e 68101) - 19³7'00" S, 4402'55" W e do Município de São Joaquim de Bicas (BHCB 68103) - 2002’31", $\mathrm{S}, 44^{\circ} 16$ ' 4"W.

Processamento do material para análises histológicas Ovários e frutos jovens, mais susceptíveis à plasmólise, foram fixados em glutaraldeído $2 \%$, em tampão fosfato $0,1 \mathrm{M}, \mathrm{pH}$ 6,8 (Gabriel 1982) e os mais desenvolvidos em FAA em etanol $50{ }^{\circ} \mathrm{GL}$ (Johansen 1940). O material foi desidratado em série etílica (Johansen 1940) e incluído em parafina ou hidroxietilmetacrilato (Tecnovit 7100). Secções seriadas de 5 a $12 \mu \mathrm{m}$ de espessura foram obtidas em micrótomo de rotação. Os cortes foram corados com safranina e azul de astra $0,5 \%$ (modificado de Bukatsch 1972) ou azul de toluidina 0,05\%, em tampão acetato 0,1 M, pH 4,4 (Feder \& O’Brien 1968). Foram utilizados floroglucinol acidificado para a detecção de lignina em células da exotesta de sementes não fixadas; lugol para a detecção de amido (Kraus \& Arduin 1997) e Sudan “black B” para a detecção de lipídios (O’Brien \& McCully 1981) em sementes fixadas em FAA em etanol $50^{\circ} \mathrm{GL}$ e incluídas em parafina. A fixação em FAA em etanol $50^{\circ} \mathrm{GL}$ 
impediu o acompanhamento da dinâmica de lipídios, permitindo apenas a detecção daqueles que resistiram ao processo de fixação. Para a realização das fotomicrografias utilizou-se fotomicroscópio Olympus BHS-BH-2.

Processamento para dissociação do tegumento e dissecação de sementes - A dissociação do tegumento da semente foi realizada em solução de peróxido de hidrogênio 20 vol. e ácido acético glacial (1:1). O material foi acondicionado em frascos tampados permanecendo em estufa a aproximadamente $50^{\circ} \mathrm{C}$ até o nível de dissociação desejado (Franklin 1945 apud Kraus \& Arduin 1997). Para uma visualização do conjunto dos embriões e da membrana que os envolve, algumas sementes foram embebidas em água destilada por 24 horas e dissecadas sob estereomicroscópio Olympus SZH.

\section{Resultados}

Semente em estádio inicial de desenvolvimento - Os óvulos são anátropos, unitegumentados e tenuinucelados. A camada mais interna do tegumento, o endotélio, é constituída por células alongadas anticlinalmente, de conteúdo citoplasmático denso com grãos de amido. $\mathrm{O}$ nucelo é representado pela epiderme nucelar e pela hipóstase que já está diferenciada em estádios iniciais do desenvolvimento (figura 1). Com o crescimento do megagametófito na região micropilar, as células da epiderme nucelar e do endotélio são degeneradas, persistindo tecidos vestigiais na região calazal (figura 2).

Após a fecundação, a semente jovem inclina-se, de modo que a rafe se posiciona paralelamente ao septo, e alonga-se nos sentidos longitudinal (figuras 3-5) e transversal. A semente em secção mediana mostra um crescimento acelerado do tegumento na região apical adjacente à hipóstase, resultante de divisões periclinais nas células calazais desta região (figuras $3,6,7$ ). As células da mesotesta proliferam-se predominantemente no lado ventral da semente onde está localizado o feixe rafeal; o lado dorsal permanece com poucas camadas celulares (figura 8). As células do endotélio dividem-se anticlinalmente acompanhando o alongamento da cavidade da semente onde estão localizados endosperma e embrião. $\mathrm{O}$ amido das células endoteliais desaparece gradativamente e o conteúdo citoplasmático torna-se mais denso (figuras 6,8). Nas regiões lateral e apical da semente as paredes anticlinais das células epidérmicas alongam-se intensamente, iniciando a formação da ala (figuras 3, 7).

Endospermogênese - A primeira divisão do endosperma é transversal, seguida por citocinese, originando uma câmara micropilar e uma câmara calazal menos volumosa (figura 9A). A segunda divisão pode ocorrer longitudinalmente nas duas células originando quatro células dispostas em duas fileiras (figura 9B) ou, em alguns casos, ocorrer transversalmente na célula da câmara micropilar originando uma fileira com três células (figura 9C). Segue-se, no primeiro caso, uma divisão transversal das células da extremidade micropilar e, no segundo, uma divisão longitudinal das três células, resultando, em ambos casos, um endosperma com seis células (figura 9D). As duas células da câmara calazal possuem citoplasma bastante denso indicando a função de haustório calazal, enquanto as da câmara micropilar possuem vacúolos grandes (figuras 9D, 10). As duas células medianas sofrem, concomitantemente, uma divisão transversal resultando em um endosperma de oito células (figura 9E). As células medianas continuam dividindo-se transversalmente, acompanhando o crescimento longitudinal da semente, de tal modo que no estádio de 16 células, o endosperma apresenta-se disposto em duas fileiras (figuras 8, 9F).

Semente em estádio médio de desenvolvimento - As células do endosperma iniciam ciclos de divisões periclinais predominantemente no pólo calazal da semente; o endosperma passa de biestratificado a multiestratificado e provoca o aumento em volume da cavidade da semente nesta região (figura 11). Num estádio seguinte, onde se observam proembriões globulares, a cavidade da semente apresenta-se intensamente alongada no sentido longitudinal (figura 12). Sua porção calazal continua aumentando em volume, enquanto a micropilar permanece muito estreita e é preenchida por células endospérmicas alongadas, de núcleos grandes, que passam a apresentar citoplasma denso (figura 12), indicando o início da função haustorial nessa região. As demais células do endosperma são menores, com citoplasma hialino e raros grãos de amido.

$\mathrm{O}$ endotélio prolifera-se em direção à região micropilar da semente e as camadas da mesotesta, adjacentes a este tecido, também podem se diferenciar em endotélio, fazendo com que se torne bi ou triestratificado (figura 13). As células periféricas do endosperma passam por vários ciclos de divisões periclinais e as paredes periclinais externas ficam justapostas às das células endoteliais (figuras 14-16). As células endospérmicas adjacentes ao haustório calazal apresentam conteúdo citoplasmático denso (figura 16).

A mesotesta é constituída por células parenquimáticas muito vacuoladas que são degeneradas nas adjacências do endotélio ao longo de toda a extensão da semente (figuras 15-16). A degeneração dessas células faz com que o conjunto endotélio-endosperma- 
embrião permaneça aderido ao restante do tegumento da semente apenas na região calazal onde se encontra a terminação do feixe rafeal e a rota de passagem de nutrientes (figura 16) e na região micropilar, através das células micropilares do endosperma e da mesotesta. Neste estádio, observam-se apenas vestígios da hipóstase (figuras 15-16). O tecido que se prolifera na região adjacente à hipóstase origina parte da mesotesta da região apical da semente e a rota de passagem de nutrientes, que estabelece o vínculo entre o conjunto endotélio-endosperma-embrião e o feixe rafeal (figura 16).

Num estádio mais avançado do desenvolvimento da semente, onde já se observam embriões em estádio de torpedo, as células endospérmicas centrais, nas adjacências do embrião, são degeneradas, enquanto que as células da periferia do endosperma, adjacentes ao endotélio, continuam se proliferando, são pequenas, quadrangulares e de conteúdo citoplasmático denso, sendo denominadas endosperma diferenciado tardiamente (figura 17).

Semente em estádio final de desenvolvimento - O endotélio e o endosperma diferenciado tardiamente envolvem o embrião que ocupa praticamente toda a cavidade da semente. O endosperma central, adjacente aos embriões, e o haustório calazal bicelular estão totalmente degradados (figura 18). Na região calazal da semente, o conjunto endotélio-endosperma-embrião permanece conectado à rota de passagem de nutrientes através das células endoteliais (figuras 18-19). O haustório micropilar multicelular está bastante desenvolvido com células volumosas, de conteúdo citoplasmático denso (figuras 20-21). A exotesta da região do corpo da semente se diferencia através da deposição de lignina nas paredes celulares (figuras 1819) e o feixe rafeal não apresenta elementos traqueais diferenciados até os estádios mais adiantados do desenvolvimento (figuras 19, 22).

O embrião é revestido pelo envoltório membranáceo, conjunto formado por endotélio, uma camada de cutícula e, internamente, pelas células do endosperma diferenciado tardiamente (figura 23). Nessa fase, o endotélio pode apresentar-se parcialmente colapsado ou com células laminares, mas está vivo, com presença de divisões anticlinais (detalhe da figura 23). No corpo da semente madura, observam-se de fora para dentro, a exotesta lignificada; a mesotesta com células parenquimáticas de aspecto frouxo apenas com poucos grãos de amido e o envoltório membranáceo envolvendo os embriões (figura 24). O envoltório membranáceo adquire formato de embrião antes mesmo que este adquira seu volume final (figura 25). Na semente dissecada, ainda é possível observar os pontos em que o envoltório membranáceo permanece aderido ao tegumento nas regiões micropilar e calazal (figura 25). As células da exotesta, na região do corpo, são alongadas periclinalmente, ricas em pontoações e muito lignificadas; o citoplasma está ausente (figura 26). As células da exotesta, na região da ala, constituem uma camada uniestratificada, possuem paredes anticlinais muito alongadas e de extremidades afiladas, paredes ricas em pontoações com uma fraca deposição de lignina, sendo o espessamento secundário reticulado e conteúdo citoplasmático ausente (figura 27).

A semente madura é achatada dorsiventralmente. O corpo, região onde estão situados os embriões, tem coloração castanho clara e apresenta-se contornado lateralmente por uma extensa ala hialina de consistência membranácea que também ocorre, de forma menos conspícua, na região apical da semente. O hilo é uma estreita cicatriz basal alongada transversalmente e situada na face ventral da semente e a rafe é vista como uma linha de coloração escura na região média do corpo também na face ventral (figura 28). O envoltório membranáceo possui coloração amarronzada e encontra-se aderido ao embrião, ou ao conjunto de embriões em sementes poliembriônicas, sendo impossível distingui-lo dos mesmos antes da dissecação (figura 29); este envoltório mantém seu formato cordiforme mesmo com a ocorrência de poliembrionia.

Figuras 1-8. Fotomicrografias de óvulos, ovários e de sementes de Tabebuia ochracea em estádio inicial de desenvolvimento. 1-3. Secção longitudinal de óvulos. 1. Fotomicrografia sob luz polarizada. Epiderme nucelar intacta. 2. Expansão do megagametófito na região micropilar. 3. Início do alongamento da semente. 4-5. Secção transversal do ovário. 4. Ovário de flor não polinizada. 5. Ovário de flor já polinizada. 6-8. Secção longitudinal de sementes jovens. 6. Proliferação do tecido adjacente à hipóstase. 78. Alongamento da semente, proliferação do endotélio e endosperma com duas fileiras. (AA = células apicais da ala; $\mathrm{AC}=$ células apicais do corpo; $\mathrm{ED}=$ endosperma; $\mathrm{EN}=$ epiderme nucelar; $\mathrm{EP}=$ epiderme; $\mathrm{ET}=$ endotélio; $\mathrm{F}=$ funículo; $\mathrm{FR}=$ feixe rafeal; $\mathrm{H}=$ hipóstase; $\mathrm{LA}=$ células laterais da ala; $\mathrm{M}=$ micrópila; $\mathrm{ME}=$ mesotesta $\mathrm{O}=$ óvulo; $\mathrm{P}=$ pericarpo; $\mathrm{PR}=$ procâmbio; $\mathrm{SM}=$ semente; $\mathrm{SP}=$ septo; $\mathrm{T}=$ tegumento; $\mathrm{VEN}=$ vestígio de epiderme nucelar). Barras $=50 \mu \mathrm{m}(1-3,6), 200 \mu \mathrm{m}(4-5,7-8)$. 

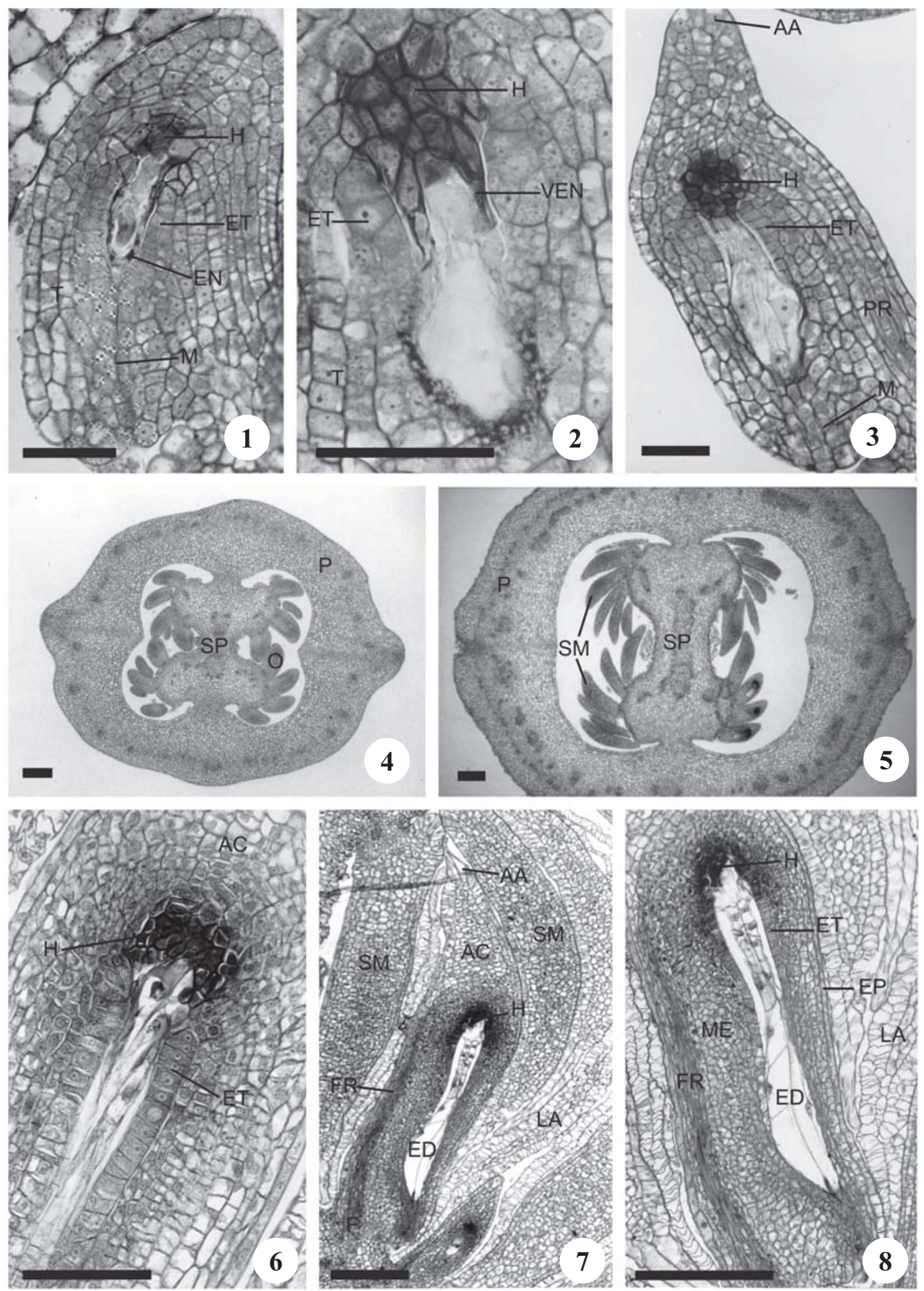

Figures 1-8. Photomicrographs of ovules, ovary, and seeds of Tabebuia ochracea at initial stages of development. 1-3. Median longitudinal section of ovules. 1. Polarized light photomicrography. Nucelar epidermis intact. 2. Expansion of megagametophyte in micropylar region. 3. Initial seed growing. 4-5. Transversal section of the ovule. 4. Non pollinated flower ovary. 5. Pollinated flower ovary. 6-8. Longitudinal section of young seeds. 6. Proliferating tissue adjacent to hypostase. 7-8. Seed stretching, endothelium proliferation and bi-layered endosperm. $(\mathrm{AA}=$ wing apical cells; $\mathrm{AC}=$ body apical cells; $\mathrm{ED}=$ endosperm; $\mathrm{EN}=$ nucelar epidermis; $\mathrm{EP}=$ epidermis; $\mathrm{ET}=$ endothelium; $\mathrm{F}=$ funiculus; $\mathrm{FR}=$ rapheal bundle; $\mathrm{H}=$ hypostase; $\mathrm{LA}=$ wing lateral cells; $\mathrm{M}=$ micropyl; $\mathrm{ME}=$ mesotest $\mathrm{O}=$ ovule; $\mathrm{P}=$ pericarp; $\mathrm{PR}=$ procambium; $\mathrm{SM}=$ seed; $\mathrm{SP}=$ septum; $\mathrm{T}=$ integument; $\mathrm{VEN}$ $=$ nucelar epidermis vestige). Bars $=50 \mu \mathrm{m}(1-3,6), 200 \mu \mathrm{m}(4-5,7-8)$. 

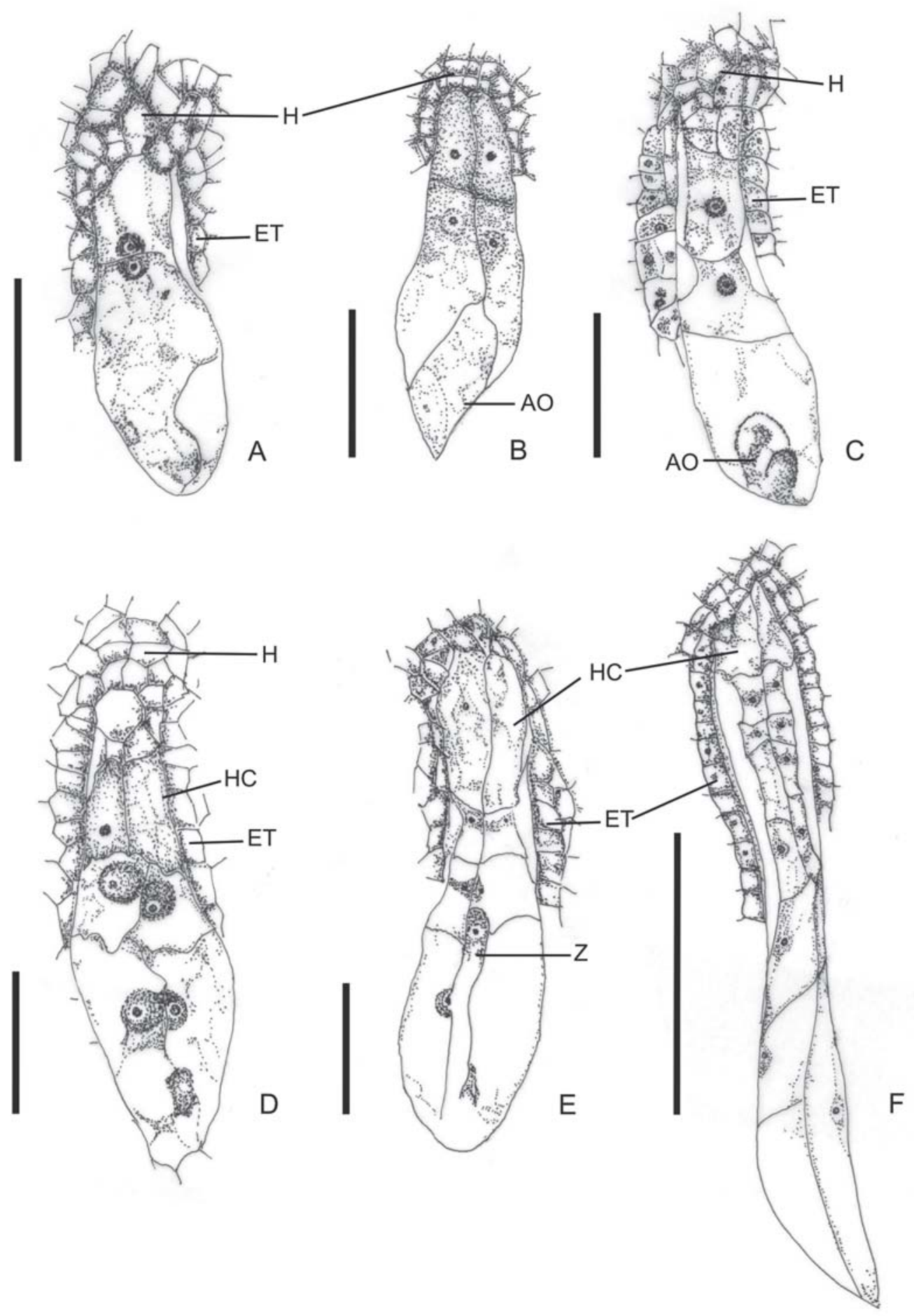

Figura 9. Secção longitudinal mediana de óvulos e sementes de Tabebuia ochracea, estádios iniciais da endospermogênese. A. Endosperma com duas células. B. Endosperma com quatro células. C. Endosperma com três células. D. Endosperma com seis células. E. Endosperma com oito células. F. Endosperma com 16 células. $(\mathrm{AO}=$ aparato oosférico; ET = endotélio; H = hipóstase; $\mathrm{HC}=$ haustório calazal; $\mathrm{Z}=$ zigoto $)$. Barras $=50 \mu \mathrm{m}(\mathrm{A}-\mathrm{E}), 200 \mu \mathrm{m}(\mathrm{F})$.

Figure 9. Median longitudinal section of ovules and seeds of Tabebuia ochracea, initial stages of endospermogenesis. A. Two-celled endosperm. B. Four-celled endosperm. C. Three-celled endosperm. D. Six-celled endosperm. E. Eight-celled endosperm. F. Sixteen-celled endosperm. $(\mathrm{AO}=$ egg cell apparatus; $\mathrm{ET}=$ endothelium; $\mathrm{H}=$ hypostase; $\mathrm{HC}=$ chalazal haustorium; $\mathrm{Z}=$ zygote). Bars $=50 \mu \mathrm{m}(\mathrm{A}-\mathrm{E}), 200 \mu \mathrm{m}(\mathrm{F})$. 


\section{Discussão}

As sementes maduras de Bignoniaceae foram descritas por Cronquist (1981) como tendo o endosperma ausente ou presente e a maioria dos trabalhos na família a descrevem como tendo ausência de endosperma ou endosperma limitado (Hyakutake \& Grotta 1965, Panizza 1967, Corner 1976, Beltrati \& Piccolo 1979, Mehra \& Kulkarni 1985, Gabrielli \& Castro 1995, Costa 1995, Ferreira \& Cunha 2000, Souza et al. 2005), como observado em Tabebuia ochracea. Devido à presença deste endosperma limitado, os termos semente albuminosa e exalbuminosa são utilizados indistintamente, de forma que um consenso para a descrição do endosperma nas sementes maduras de Bignoniaceae é de grande importância taxonômica. Os termos semente albuminosa e exalbuminosa, respectivamente, dão a idéia do endosperma como sendo, ou não, a principal fonte de energia utilizada pelo embrião durante a germinação da semente, sendo aconselhável referir-se a essas sementes com pequenas quantidades de endosperma como exalbuminosas, como já havia sido sugerido por Esau (1985).

O endosperma celular desde o início do seu desenvolvimento é característico das espécies de Bignoniaceae (Mauritzon 1935, Ghatak 1956, Davis 1966, Mehra \& Kulkarni 1985, Shivaramiah 1998, Bittencourt Júnior et al. 2003, Bittencourt Júnior \& Semir 2005) e, a presença dos haustórios micropilar e calazal é referida para toda a ordem Lamiales (Judd et al. 2002). Após a formação das câmaras micropilar e calazal do endosperma, parece ser mais comum a divisão longitudinal de ambas células (Mehra \& Kulkarni 1985, Bittencourt Júnior et al. 2003, Bittencourt Júnior \& Semir 2005), do que a divisão transversal na câmara micropilar (Bittencourt Júnior et al. 2003, Bittencourt Júnior \& Semir 2005). O desenvolvimento do endosperma em $T$. ochracea segue o tipo Catalpa segundo Mauritzon (1935), bem como as demais espécies do gênero já estudadas (Mehra \& Kulkarni 1985, Shivaramiah 1998, Bittencourt Júnior et al. 2003, Bittencourt Júnior \& Semir 2005). Di Fulvio (1983) estabeleceu um sistema de classificação para o endosperma utilizando uma nomenclatura única para todos os grupos de angiospermas, ao invés da comumente utilizada para famílias. Segundo este sistema, o endosperma de $T$. ochracea é classificado como do megatipo celular, heteropolar micropilar e subtipo variável, dada a presença das seguintes características: ser celular desde o início; ter a parede formada no primeiro ciclo mitótico com orientação transversal; ter somente a célula da câmara micropilar formando o tecido de reserva, enquanto a da calazal forma um haustório, e ter o segundo ciclo mitótico formando paredes longitudinais ou transversais.

Os haustórios endospérmicos são muito freqüentes na endospermogênese celular; eles podem ser classificados como haustórios primários, que se originam nos pólos do endosperma a partir das primeiras divisões celulares e, secundários, que são os que se diferenciam em estádios tardios do desenvolvimento (Di Fulvio 1983). Há um consenso sobre o haustório calazal primário bicelular nas espécies até então estudadas de Tabebuia (Mehra \& Kulkarni 1985, Shivaramiah 1998, Bittencourt Júnior \& Semir 2005), sendo também encontrado em espécies de outros gêneros da família como Bignonia megapotamica (Swamy 1941) e Parmentiera cereifera. (Govindu 1950). O haustório calazal do endosperma de $T$. ochracea tem comportamento semelhante ao observado para $T$. rosea (Mehra \& Kulkarni 1985), degradando gradualmente as células da hipóstase e desaparecendo totalmente, enquanto o haustório micropilar permanece ativo até a maturidade da semente.

Em T. ochracea, no endosperma com seis células, as duas células da câmara micropilar são muito volumosas, vacuoladas e contribuem para a formação do haustório micropilar, que é diferenciado mais tardiamente, ao tornar-se multicelular e com células de conteúdo citoplasmático denso, como também foi observado em T. rosea (Mehra \& Kulkarni 1985). Em Tabebuia impetiginosa, as duas células da câmara micropilar também são muito volumosas e vacuoladas (Bittencourt Júnior \& Semir 2005) e, em T. pallida, estas células são reportadas, desde o seu surgimento, como haustório micropilar do endosperma (Shivaramiah 1998), embora o aspecto haustorial mencionado por Mehra \& Kulkarni (1985), que consiste de células fortemente hipertrofiadas, com citoplasma denso e vacuolado não tenha ficado evidente. Segundo Mauritzon (1935), na família Bignoniaceae, as células da câmara micropilar podem se organizar num haustório bem diferenciado com células proeminentes; ou permanecer apenas como células distintas; ou ainda, podem incorporar-se às demais células endospérmicas. As espécies até então estudadas no gênero Tabebuia parecem enquadrar-se no grupo que possui células distintas das demais, embora contribuam para a formação do haustório nos estádios mais avançados do desenvolvimento. É importante ressaltar que, embora as células da câmara micropilar contribuam para a formação do haustório nessa região, o momento e a 

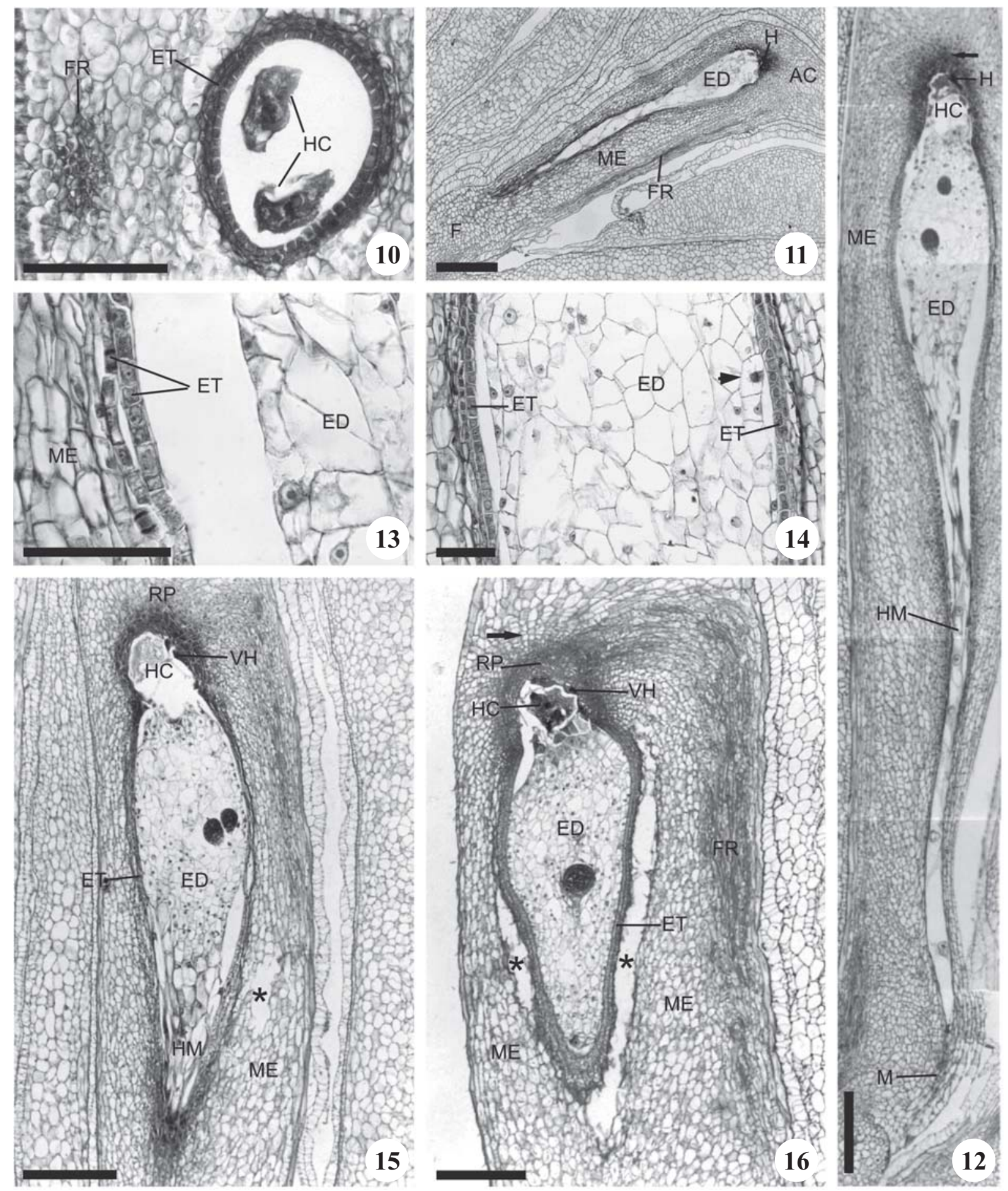

Figuras 10-16. Fotomicrografias de sementes de Tabebuia ochracea em estádio médio de desenvolvimento. 10. Secção transversal de semente. Haustório calazal com duas células. 11-16. Secção longitudinal mediana de sementes. 11. Expansão do endosperma. 12. Expansão da cavidade da semente no sentido longitudinal e diferenciação do haustório micropilar. 13. Diferenciação de uma segunda camada do endotélio. 14. Divisões periclinais na periferia do endosperma (cabeça de seta). 15. Início da degeneração da mesotesta adjacente ao endotélio. 16. Endosperma e endotélio aderidos entre si, contornando o embrião e separados do restante da mesotesta. Apenas vestígios da hipóstase estão presentes. A seta aponta parte da mesotesta que se originou do tecido em proliferação adjacente à hipóstase. $(\mathrm{AC}=$ células apicais do corpo; $\mathrm{ED}=$ endosperma; $\mathrm{ET}=$ endotélio; $\mathrm{F}=$ funículo; $\mathrm{FR}=$ feixe rafeal; $\mathrm{H}=$ hipóstase $; \mathrm{HC}=$ haustório calazal; $\mathrm{HM}=$ haustório micropilar; $\mathrm{M}=$ micrópila; $\mathrm{ME}=$ mesotesta, $\mathrm{RP}=$ rota de passagem de nutrientes; $\mathrm{VH}=$ vestígios de hipóstase). Os asteriscos indicam o espaço deixado entre o endotélio e a mesotesta. Barras $=50 \mu \mathrm{m}(10,13-14), 200 \mu \mathrm{m}(11-12,15-16)$. 
forma em que este haustório se diferencia determinam o seu tipo segundo a classificação de Di Fulvio (1983). A diferenciação tardia deste haustório em $T$. ochracea e em T. rosea faz com que ele seja classificado como multicelular, diferenciado tardiamente e secundário (Di Fulvio 1983).

O endotélio está envolvido em vários processos durante o desenvolvimento embrionário, principalmente quando o nucelo é pouco abundante e totalmente absorvido (Werker 1997), como é o caso da família Bignoniaceae. A alteração do endotélio, de rico em grãos de amido para um tecido de células desprovidas destes e com citoplasma denso, provavelmente indica uma mudança funcional como sugerido por Kapil \& Tiwari (1978). A extensão do endotélio varia entre famílias e até mesmo entre gêneros (Kapil \& Tiwari 1978); em $T$. ochracea, ele envolve todo o megagametófito até ser degenerado na porção micropilar. A degeneração da epiderme nucelar e do endotélio apenas na região micropilar do óvulo é observada por diversos autores em espécies de Bignoniaceae (Mauritzon 1935, Swamy 1941, Govindu 1950, Ghatak 1956, Mehra \& Kulkarni 1985, Galati \& Strittmatter 1999). À medida que a cavidade da semente se alonga, o endotélio prolifera-se a partir da porção calazal, envolvendo a porção mediana, podendo coordenar o crescimento dos componentes do óvulo durante o crescimento intensivo do endosperma e do embrião (Kapil \& Tiwari 1978, Werker 1997), além de participar da transferência, acúmulo temporário e metabolização de nutrientes (Werker 1997).

Provavelmente, a degeneração das células parenquimáticas da mesotesta em T. ochracea, também observada em T. chrysotricha (Souza et al. 2005), é provocada por enzimas secretadas pelas células endoteliais, sendo essas impedidas de atuar sobre o endosperma e o embrião devido à espessa cutícula presente nas paredes periclinais internas do endotélio (Kapil \& Tiwari 1978, Werker 1997). Essa cutícula ainda impede que os nutrientes presentes no endosperma se desloquem para a mesotesta e permite uma distinção entre as porções endospérmica e endotelial do envoltório membranáceo. Devido à presença da cutícula, a translocação de nutrientes deve ser efetuada preferencialmente nas regiões micropilar e calazal, sendo facilitada pela degeneração precoce das células do endotélio na região micropilar e pela presença de hipóstase na calazal, além de corresponder à localização dos haustórios do endosperma.

A formação de uma estrutura membranácea que envolve os embriões é comum dentre espécies de Bignoniaceae (Hyakutake \& Grotta 1965, Panizza 1967, Beltrati \& Piccolo 1979, Mehra \& Kulkarni 1985, Gabrielli \& Castro 1995, Costa 1995, Souza et al. 2005), provavelmente, tendo a mesma função, embora sua constituição apresente variações. Em $T$. ochracea, o envoltório membranáceo está localizado entre o embrião e a testa da semente e é constituído por uma associação entre endosperma e endotélio, também verificada em T. chrysotricha (Souza et al. 2005). É possível que em todas as espécies que apresentam o envoltório membranáceo, sua ontogenia e constituição sejam semelhantes, dados os importantes eventos para a formação deste tecido. Os estudos que descrevem o nucelo como constituinte do envoltório membranáceo, provavelmente, não puderam acompanhar os estádios iniciais de desenvolvimento e sua degeneração e os que descrevem apenas endosperma, podem ter tido dificuldade na visualização do endotélio, devido à semelhança de suas células às do endosperma diferenciado tardiamente e à ocorrência de células colapsadas.

O formato do envoltório membranáceo de $T$. ochracea torna-se muito semelhante ao de um embrião típico maduro, provavelmente devido à natureza do endosperma (como geração triplóide). O endosperma periférico diferenciado tardiamente ainda não havia sido reportado para as Bignoniaceae, mas já havia sido

Figures 10-16. Photomicrographs of seeds of Tabebuia ochracea in median stage of development. 10. Transversal section of seed. Two-celled chalazal haustorium. 11-16. Median longitudinal section of seeds. 11. Endosperm expansion. 12. Longitudinal expansion of the seed cavity and differentiation of the micropylar haustorium. 13. Second layer differentiation of the endothelium. 14. Periclinal divisions at the endosperm periphery (arrow head). 15. Mesotest close to endothelium beginning degeneration. 16. Endosperm and endothelium adhere to each other, both involving the embryo and being separated from the rest of mesotest. Only hypostase vestiges are present. 12, 16. The arrow points out part of the mesotest witch arises from the proliferating tissue behind hypostase. $(\mathrm{AC}=$ apical cells of body; $\mathrm{ED}=$ endosperm; $\mathrm{ET}=$ endothelium; $\mathrm{F}=$ funiculus; $\mathrm{FR}=$ rapheal bundle; $\mathrm{H}=$ hypostase $; \mathrm{HC}=$ chalazal haustorium; $\mathrm{HM}=$ micropylar haustorium; $\mathrm{M}=$ micropyl; $\mathrm{ME}=$ mesotest, $\mathrm{RP}=$ nutrients passage route; $\mathrm{VH}=$ hypostase vestige). The asterisks point the space between endothelium and mesotest. Bars $=$ $50 \mu \mathrm{m}(10,13-14), 200 \mu \mathrm{m}(11-12,15-16)$. 

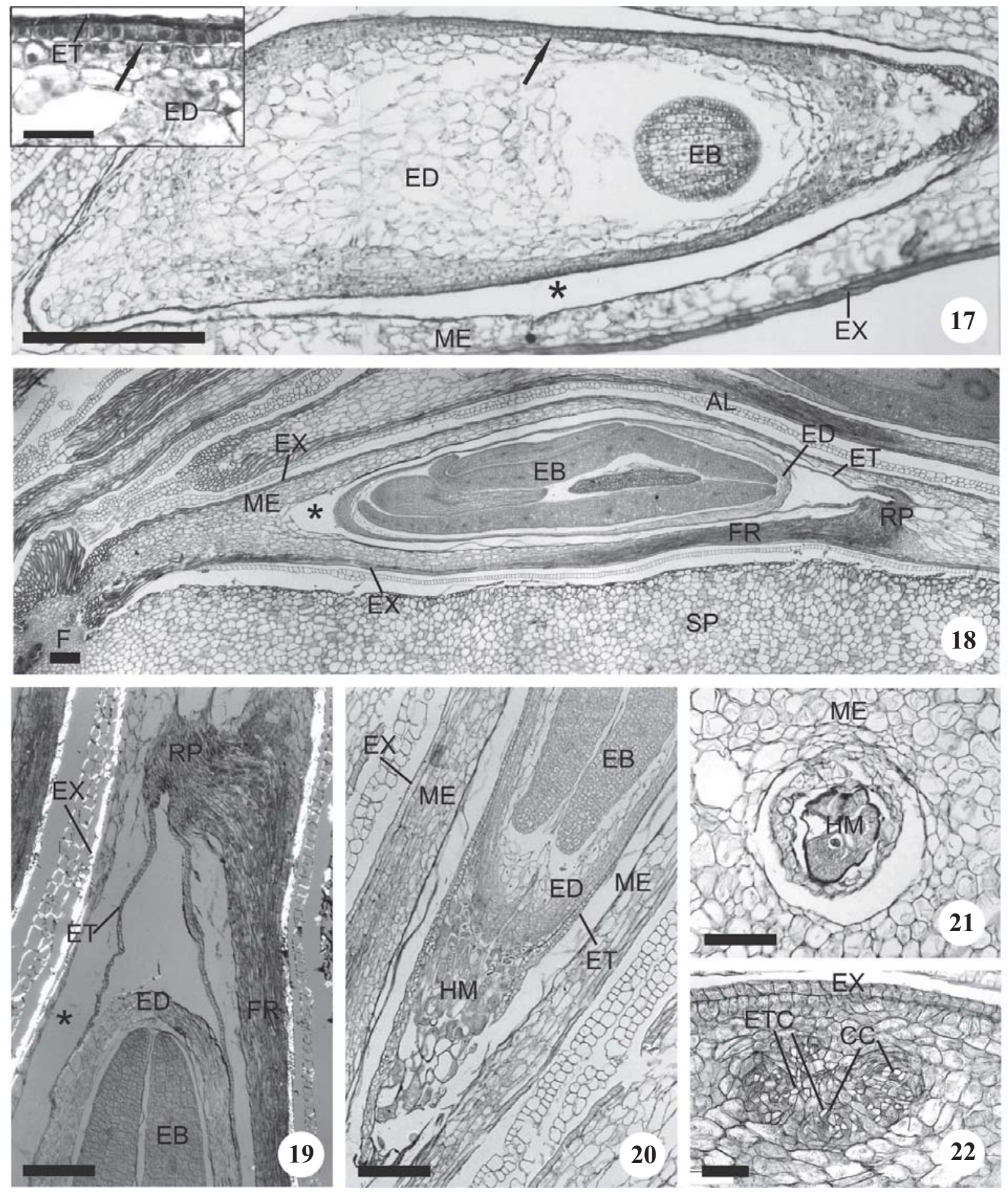

Figuras 17-22. Fotomicrografias de sementes de Tabebuia ochracea em estádios médio e tardio de desenvolvimento. 17-20. Secção longitudinal de sementes. 17. Células diferenciadas na periferia do endosperma-endosperma diferenciado tardiamente (setas e detalhe no canto superior esquerdo). 18-19. Endosperma periférico e endotélio circundando os embriões e ligados à rota de passagem. Haustório calazal totalmente degenerado. 19. Fotomicrografia sob luz polarizada. Detalhe da figura 18, região calazal da semente. 20. Haustório micropilar persistente. 21-22. Secção transversal de sementes. 21. Célula do haustório micropilar na extremidade da semente. 22 . Feixe rafeal com elementos de tubo crivado e células companheiras diferenciados; os elementos traqueais não estão diferenciados. $(\mathrm{AL}=$ células laterais da ala; $\mathrm{CC}=$ células companheiras; $\mathrm{EB}=$ embrião; $\mathrm{ED}=$ endosperma; $\mathrm{ET}=$ endotélio; $\mathrm{ETC}=$ elementos de tubo crivado; $\mathrm{EX}=$ exotesta; $\mathrm{FR}=$ feixe rafeal; $\mathrm{HM}$ = haustório micropilar; $\mathrm{ME}$ $=$ mesotesta; $\mathrm{RP}=$ rota de passagem de nutrientes; $\mathrm{SP}=$ septo). Os asteriscos indicam o espaço deixado entre o endotélio e a mesotesta. Barras $=200 \mu \mathrm{m}(17-20), 50 \mu \mathrm{m}(21-22 \mathrm{e}$ detalhe da figura 17). 
descrito para Tridax procumbens L. - Asteraceae (Padmanabhan 1962), podendo ter uma ampla distribuição. $\mathrm{O}$ envoltório membranáceo pode ter adquirido diversas funções, dentre elas a de impedir o deslocamento de nutrientes, criar um espaço de ar que auxilie na flutuabilidade da semente através do rompimento com a mesotesta, controlar o desenvolvimento dos embriões e ter alguma utilidade durante a germinação das sementes. Embora não tenham sido verificados compostos fenólicos no endotélio de $T$. ochracea, a coloração amarronzada verificada no envoltório membranáceo tem sido relacionada à sua presença nesse tecido (Beltrati \& Piccolo 1979; Von Teichman \& Van Wyk 1991).

As paredes das células da hipóstase, em $T$. ochracea, apresentam um espessamento péctico e um acúmulo de compostos fenólicos, como verificado para Tabebuia pulcherrima (Bittencourt Júnior \& Mariath 2002), entretanto, a presença de lignina é questionada por Costa et al. (2004), uma vez que estas células se diferenciam em embriões adventícios, o que gera a necessidade de maiores investigações. Carboidratos diferentes do amido foram verificados nas células da hipóstase em T. ochracea (Costa et al. 2004), em Ornithogalum caudatum Aiton (Tilton 1980) e em T. pulcherrima (Bittencourt Júnior \& Mariath 2002), podendo estar relacionados com a função nutritiva deste tecido (Tilton 1980). O tecido que se prolifera na região calazal da semente, tem características meristemáticas, provavelmente tendo origem nas células nucelares da hipóstase ou das adjacências, ele origina a rota de passagem de nutrientes (Tilton 1980) e a porção apical do tegumento da semente. Provavelmente, a estrutura mencionada como hipóstase nos estádios mais adiantados do desenvolvimento (Swamy 1941, Govindu 1950, Souza et al. 2005) corresponde a seu conceito sensu lato, o qual engloba a rota de passagem de nutrientes (Tilton 1980), motivo pelo qual esta última não é mencionada nestes trabalhos. Assim, a utilização de termos distintos como, hipóstase e rota de passagem de nutrientes para modificações específicas foi considerada menos vaga e confusa, concordando com o exposto por Tilton (1980).

A diferenciação do tegumento da semente é muito similar para as espécies de Bignoniaceae exotestais (Corner 1976). Entretanto, as paredes das células da ala apresentam diferentes graus de lignificação para as espécies já estudadas (Govindu 1950, Ghatak, 1956, Costa 1995, Souza et al. 2005); ressalta-se, no gênero Tabebuia, a não lignificação ou uma muito sutil em $T$. chrysotricha (Souza et al. 2005) e T. ochracea, consideradas espécies próximas (Gentry 1992), enquanto T. serratifolia. apresenta células da ala claramente lignificadas (Costa 1995).

$\mathrm{O}$ fato de não terem sido observados elementos traqueais diferenciados no feixe rafeal da semente de $T$. ochracea, coincide com o descrito para espécies de Begoniaceae e Gentianaceae, nas quais menciona-se uma aparência procambial dessa estrutura (Bouman 1984). Entretanto, o mesmo tecido é mencionado, em outras espécies de Bignoniaceae, como um cordão de células de conteúdo citoplasmático denso, que estabelece conexão entre as células calazais e os traços vasculares na base do óvulo, participando na condução de nutrientes (Swamy 1941, Govindu 1950). Em T. serratifolia (Costa 1995) e Tabebuia vellosoi Toledo (M.E. Costa, dados não publicados), a diferenciação dos elementos traqueais no feixe rafeal demonstra a plasticidade desse caráter no gênero.

A presença concomitante de óvulos anátropos, unitegumentados, tenuinucelados, com diferenciação de endotélio e de um endosperma celular, em Bignoniaceae (Davis 1966), indica que estes são caracteres derivados dentre as angiospermas (Kapil \& Tiwari 1978, Von Teichman \& Van Wyk 1991), sendo que, óvulos unitegumentados e tenuinucelados ainda corroboram dados moleculares que incluem a ordem Lamiales no Clado Asteridae (Judd et al. 2002). A

Figures 17-22. Photomicrographs of seeds of Tabebuia ochracea in median and late stages of development. 17-20. Seed longitudinal section. 17. Differentiated cells at the endosperm periphery - latter differentiated endosperm (arrows and detail in the upper left side). 18-19. Peripheral endosperm and endothelium are involving embryos and linked to the passage route. Chalazal haustorium totally degenerated. 19. Polarized light photomicrography. Detail of figure 18, seed chalazal region. 20. Micropylar haustorium persistent. 21-22. Seed transversal section. 21. Micropylar haustorium cell at seed extremity. 22. Rapheal bundle with differentiated sieve tube elements and companion cells. $(\mathrm{AL}=$ wing lateral cells; $\mathrm{CC}=$ companion cells; $\mathrm{EB}=$ embryo; $\mathrm{ED}=$ endosperm; $\mathrm{ET}=$ endothelium; $\mathrm{ETC}=$ sieve tube elements; $\mathrm{EX}=$ exotest $\mathrm{FR}=$ rapheal bundle; $\mathrm{HM}=$ micropylar haustorium; $\mathrm{ME}=$ mesotest; $\mathrm{RP}=$ nutrients passage route; $\mathrm{SP}=$ septum). The asterisks point the space between endothelium and mesotest. Bars $=200 \mu \mathrm{m}(17-20), 50 \mu \mathrm{m}(21-22$ and detail of figure 17). 


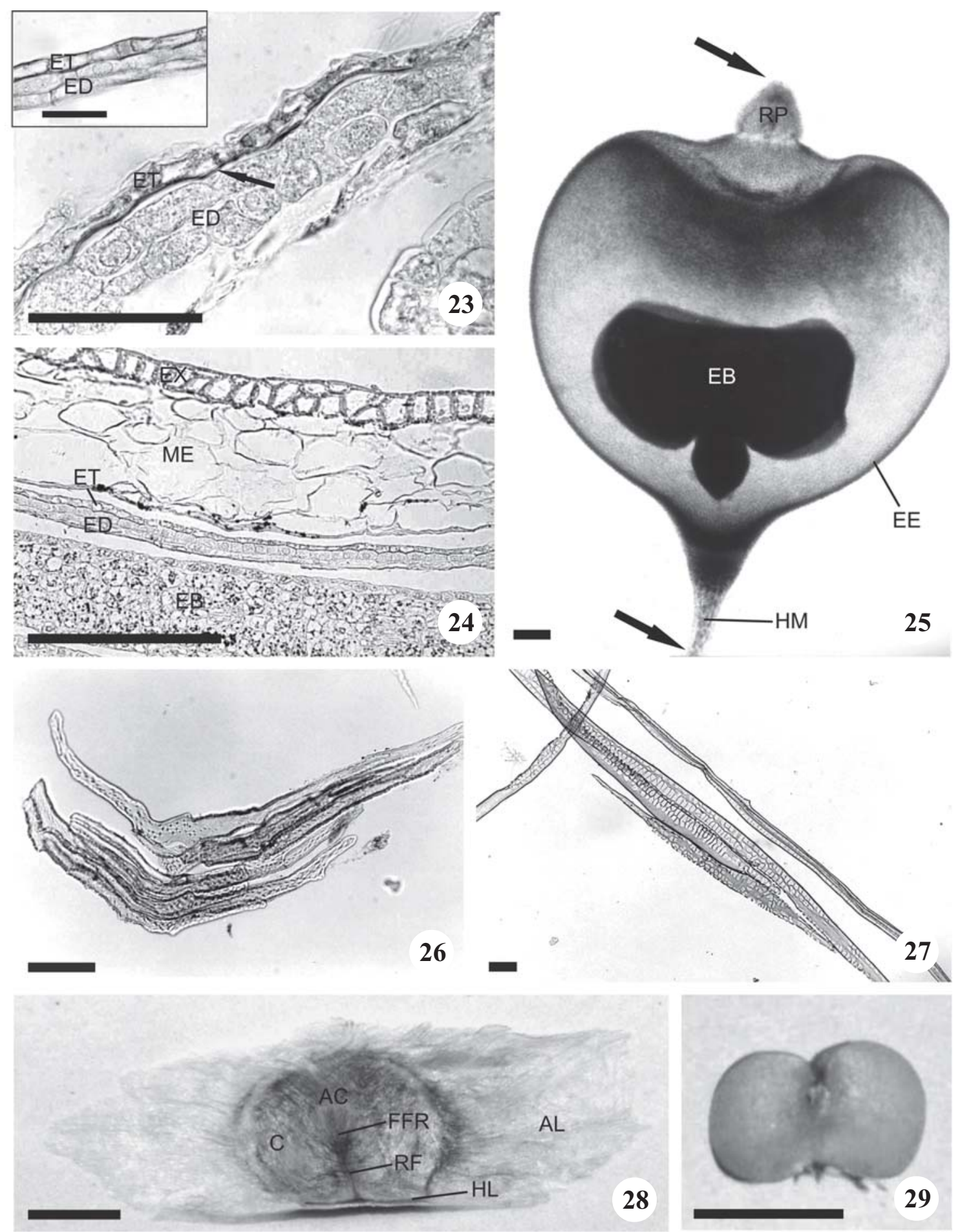

Figuras 23-29. Sementes de Tabebuia ochracea em estádio tardio de desenvolvimento. 23-24. Secção longitudinal de semente madura. 23. Envoltório membranáceo (teste com Sudam "Black"). A seta aponta a cutícula entre o endotélio e o endosperma. Em detalhe uma divisão anticlinal no endotélio. 24. Estruturas da semente madura (teste com lugol). 25. Semente dissecada; conjunto embrião-envoltório membranáceo. Regiões de aderência ao tegumento (setas). 26-27. Macerados de células da exotesta. 26. Região do corpo da semente. 27. Região das alas laterais. 28. Vista ventral da semente. 29. Semente dissecada; envoltório membranáceo e embrião. Não é possível distinguir o envoltório do embrião devido à aderência entre as estruturas. $(\mathrm{AC}=$ região apical do corpo da semente; $\mathrm{AL}=$ ala da região lateral da semente $; \mathrm{C}=$ corpo da semente $; \mathrm{EB}=\mathrm{embrião} ; \mathrm{ED}=$ endosperma; $\mathrm{EE}=$ conjunto endotélio-endosperma; $\mathrm{ET}=$ endotélio; $\mathrm{EX}=$ exotesta; $\mathrm{FFR}=$ extremidade do feixe rafeal; $\mathrm{HL}=$ hilo; $\mathrm{HM}=$ haustório micropilar; $\mathrm{ME}=$ mesotesta; $\mathrm{RF}=$ rafe, $\mathrm{RP}=$ rota de passagem de nutrientes $).$ Barras $=50 \mu \mathrm{m}(23), 25 \mu \mathrm{m}$ (detalhe da figura 23), $200 \mu \mathrm{m}$ (24-27), 0,5 mm (28-29). 
hipóstase, embora esteja mais comumente associada a caracteres basais (Kapil \& Tiwari 1978, Von Teichman \& Van Wyk 1991), também ocorre nas espécies dessa família (Davis 1966). A ocorrência concomitante de endotélio e hipóstase, verificada para a maioria das espécies de Bignoniaceae (Davis 1966, Mehra \& Kulkarni 1985, Galati \& Strittmatter 1999, Bittencourt Júnior \& Mariath 2002, Souza et al. 2005), é considerada um aspecto raro, reportado apenas para nove famílias de angiospermas (Von Teichman \& Van Wyk 1991).

A semelhança no desenvolvimento do endosperma entre as espécies do gênero Tabebuia demonstram o valor de características embriológicas em sistemática e sua grande conservação, com mínimas variações intraespecíficas (Bittencourt Júnior et al. 2003, Bittencourt Júnior \& Semir 2005). Uma explanação mais clara da ontogenia do envoltório membranáceo foi realizada no trabalho de Souza et al. (2005) com $T$. chrysotricha e agora no presente, confirmando sua dupla origem e atentando para detalhes do desenvolvimento dessa estrutura. Provavelmente, todas as espécies que apresentam o envoltório membranáceo, têm sua ontogenia e constituição semelhantes, dados os importantes eventos para a formação deste tecido, como a degradação das células da mesotesta, a longa funcionalidade das células do endotélio e sua aderência às células do endosperma que se diferenciam tardiamente. A utilização de termos individuais para modificações específicas como hipóstase e rota de passagem de nutrientes é considerada menos vaga e confusa (Tilton 1980), sendo adotada no presente. Características do tegumento da semente nos estádios finais de desenvolvimento ainda parecem ser úteis para a sistemática da família e do gênero, merecendo ser melhor exploradas.

Agradecimentos - Ao Prof. Dr. Nelson Sabino Bittencourt Júnior, pelo constante estímulo e importantes sugestões. Ao
Departamento de Botânica da UFMG, pelo suporte técnico e uso das dependências do laboratório de Anatomia Vegetal. À Profa. Dra. Rosy Mary dos Santos Isaias, por ter nos recebido neste laboratório e pela sugestão do termo "envoltório membranáceo". À Profa. Dra. Daniela Simão, pelas correções dos trechos em inglês. Aos revisores anônimos, pelas sugestões que permitiram uma grande melhoria na qualidade do trabalho. As autoras ainda agradecem ao PROBIC-PUC$\mathrm{MG}$, pela bolsa de iniciação científica da primeira autora, e à CAPES, pela bolsa de doutorado da segunda autora.

\section{Referências bibliográficas}

BELTRATI, C.M. \& PICCOLO, A.L.G. 1979. Consideraciones sobre la semilla, la germinación y la plántula de Distictella mansoana (Bur.) Urb. Phytton 37:85-96.

BITTENCOURT JÚNIOR, N.S. \& MARIATH, J.E.A. 2002. Ovule ontogeny of Tabebuia pulcherrima Sandwith (Bignoniaceae): megasporogenesis and integument development. Revista Brasileira de Botânica 25:103-115.

BITTENCOURT JÚNIOR, N.S. \& SEMIR, J. 2005. Late-acting self-incompatibility and other breeding systems in Tabebuia (Bignoniaceae). International Journal of Plant Sciences 166:493-506.

BITTENCOURT JÚNIOR, N.S., GIBBS, P.E. \& SEMIR, J. 2003. Histological study of post-pollination events in Spathodea campanulata Beauv. (Bignoniaceae), a species with late-acting self-incompatibility. Annals of Botany 91:827-834.

BOUMAN, F. 1984. The ovule. In Embryology of angiosperms (B.M. Johri, ed.). Springer-Verlag, Berlin, p.123-157.

BUKATSCH, F. 1972. Bemerkungen zur doppelfärbung astrablau-safranin. Mikrofosmos 61:255.

CORNER, E.J.H. 1976. The seed of dicotiledons. Cambrige University Press, London.

COSTA, M.E. 1995. Morfo-anatomia da semente e da plântula de Tabebuia serratifolia (Vahl) Nicholson (Bignoniaceae). Dissertação de mestrado, Universidade Federal do Paraná, Curitiba.

COSTA, M.E., SAMPAIO, D.S., PAOLI, A.A.S. \& LEITE, S.C.A.L. 2004. Poliembrionia e aspectos da embriogênese em Tabebuia ochracea (Chamisso) Standley (Bignoniaceae). Revista Brasileira de Botânica 27:395-406.

Figures 23-29. Seeds of Tabebuia ochracea in late stages of development. 23-924. Mature seed longitudinal section. 23. Membranaceous envelope (Sudam Black test). The arrow points the cuticle between endothelium and endosperm. In detail an anticlinal division in the endothelium. 24. Mature seed structures (lugol test). 25. Dissected seed; embryo-membranaceous envelop group. Regions of adherence to the tegument (arrows). 26-27. Macerate of the exotest cells. 26. Seed body. 27. Lateral wing region. 28. Seed ventral view. 29. Dissected seed; membranaceous envelop and embryo. Its impossible to distinguish membranaceous envelop and embryo due to the adherence between them. $(\mathrm{AC}=$ apical region of seed body; $\mathrm{AL}=$ wing of seed lateral region; $\mathrm{C}=$ seed body; $\mathrm{EB}=$ embryo; $\mathrm{ED}=$ endosperm; $\mathrm{EE}=$ endosperm-endothelium conjunct; $\mathrm{ET}=\mathrm{endothelium;} \mathrm{EX}$ $=$ exotest; FFR = rapheal bundle end; $\mathrm{HL}=$ hilo; $\mathrm{HM}=$ micropylar haustorium; $\mathrm{ME}=$ mesotest; $\mathrm{RF}=$ raphe, $\mathrm{RP}=$ nutrients passage route). Bars $=50 \mu \mathrm{m}(23), 25 \mu \mathrm{m}$ (detail of figure 23), $200 \mu \mathrm{m}(24-27), 0,5 \mathrm{~mm}(28-29)$. 
CRONQUIST, A. 1981. An integrated system of classification of flowering plants. Columbia University Press, New York.

DAVIS, O.L. 1966. Systematic embryology of the Angiosperms. John Wiley \& Sons, Inc., New York.

DIFULVIO, T.E. 1983. Los “tipos" de endosperma y de haustorios endospermicos. Su clasificacion. Kurtziana 16:7-31.

ESAU, K. 1985. Anatomía vegetal. $3^{\text {rd }}$ ed. Omega, Barcelona.

FAHN, A. 1990. Plant anatomy. $4^{\text {th }}$ ed. Pergamon Press, New York.

FEDER, N. \& O’BRIEN, T.P. 1968. Plant microtechnique; some principles and new methods. American Journal of Botany 55:123-142.

FERREIRA, R.A. \& CUNHA, M.C.L. 2000. Aspectos morfológicos de sementes, plântulas e desenvolvimento da muda de craibeira (Tabebuia caraiba (Mart.) Bur.) Bignoniaceae e pereiro (Aspidosperma pyrifolium Mart.) -Apocynaceae. Revista Brasileira de Sementes 22:134-143.

GABRIEL, B.L. 1982. Biological Electron Microscopy. Van Nostrand Reinhold, New York.

GABRIELLI, A.C. \& CASTRO, M.M. 1995. Anatomia da semente madura de Pyrostegia venusta (Ker.) Miers Bignoniaceae. Revista Brasileira de Botânica 18:227-234.

GALATI, B.G. \& STRITTMATTER, L.I. 1999. Ovule ontogeny and megasporogenesis in Jacaranda mimosifolia D. Don. (Bignoniaceae). Phytomorphology 49:67-74.

GENTRY, A.H. 1992. Bignoniaceae - Part II (Tribe Tecomeae). Flora Neotropica. Monograph 25:1-370.

GHATAK, J. 1956. A contribution to the life-history of Oroxylum indicum Vent. Proceedings of the Indian Academical Science 43:72-87.

GOVINDU, H.C. 1950. Studies in the embryology of some members of the Bignoniaceae. Proceedings of the Indian Academical Science 32:164-178.

HYAKUTAKE, S. \& GROTTA, A.S. 1965. Contribuição ao estudo morfológico e anatômico de Anemopaegma arvense (Vell.) Stellfeld. var. petiolata Bur. Bignoniaceae. Revista da Faculdade de Farmácia e Bioquímica de São Paulo 3:51-78.

JOHANSEN, D.A. 1940. Plant microtechenique. Mc GrawHill Book Company, New York.

JUDD, W.S., CAMPBELL, C.S., KELLOGG, E.A., STEVENS, P.F. \& DONOGHUE, M.J. 2002. Plant Systematics - A Phylogenetic Approach. $2^{\text {nd }}$ ed. Sinauer Associates Inc, Sunderland.
KAPIL, R.N. \& TIWARI, S.C. 1978. The integumentary tapetum. The Botanical Review 44:457-490.

KRAUS, J.E. \& ARDUIN, M. 1997. Manual básico de métodos em morfologia vegetal. EDUR, Seropédica.

LORENZI, H. 2000. Árvores brasileiras: manual de identificação e cultivo de plantas arbóreas nativas do Brasil Instituto Plantarum, Nova Odessa.

MAURITZON, J. 1935. Etwas uber die embryologie der Bignoniaceen. Botaniska Notser 1935:60-77.

MEHRA, K.R. \& KULKARNI, A.R. 1985. Embryological studies in Bignoniaceae. Phytomorphology 35:239-251.

O'BRIEN, T.P. \& MCCULLY, M.E. 1981. The study of plant structure principles and selected methods. Termarcarphi Pty Ltd, Melbourne.

PADMANABHAN, D. 1962. A reinvestigation of the endosperm and endothelium in Tridax procumbens $\mathrm{L}$. Phytomorphology 12:356-361.

PANIZZA, S. 1967. Contribuição ao estudo morfológico e anatômico de Jacaranda caroba (Velloso) DC. Bignoniaceae. Revista da Faculdade de Farmácia e Bioquímica de São Paulo 5:93-106.

SHIVARAMIAH, G. 1998. Endosperm development in Bignoniaceae. Phytomorphology 48:45-50.

SILVA, L.L. \& PAOLI,A.A.S. 2000. Caracterização morfoanatômica da semente de Zanthoxylum rhoifolium Lam. -Rutaceae. Revista Brasileira de Sementes 22:250-256.

SOUZA, L.A, IWAZAKI, M.C. \& MOSCHETA, I. 2005. Morphology of the pericarp and seed of Tabebuia chrysotricha (Mart. ex DC.) Standl. (Bignoniaceae). Brazilian Archives of Biology and Technology 48:407-418.

SWAMY, B.G.L. 1941. Contributions to the life history of Bignonia megapotamica. Journal of the Indian Botanical Society 20:299-305.

TILTON, V.R. 1980. Hypostase development in Ornithogalum caudatum (Liliaceae) and notes on other types of modifications in the chalaza of angiosperm ovules. Canadian Journal of Botany 58:2059-2066.

VON TEICHMAN, I. \& VAN WYK, A.E. 1991. Trends in evolution of dicotyledonous seeds based on character associations, with special reference to pachychalazy and recalcitrance. Botanical Journal of the Linnean Society 105:211-237.

WERKER, E. 1997. Seed anatomy. Gebrüder Borntraeger, Berlin. 